\title{
A Distinct Population of Islet Cells Defines Diffuse Congenital Hyperinsulinism in Infancy but Not Other Forms of the Disease
}

\author{
B Han ${ }^{1}$, M Newbould², G Batra², E Cheesman², RJ Craigie², Z Mohamed ${ }^{1,2}$, L Rigby², R Padidela², \\ M Skae $^{2}$, A Mironov ${ }^{1}$, T Starborg ${ }^{1}$, KE Kadler ${ }^{1}$, KE Cosgrove ${ }^{* 1}$, I Banerjee ${ }^{2}$, MJ. Dunne ${ }^{* 1}$
}

${ }^{1}$ Faculty of Life Sciences, University of Manchester ${ }^{2}$ Central Manchester University Hospitals NHS Foundation Trust (CMFT) Oxford Road, Manchester, M13 9PT, UK

\section{Background}

Congenital Hyperinsulinism in Infancy $(\mathrm{CHI})$ mainly arises due to mutations in ATP-sensitive K-channel genes (ABCC8 and KCNJ11). However, the expression pattern of defects can be markedly diverse. In diffuse $\mathrm{CHI}(\mathrm{CHI}-\mathrm{D})$ all islet cells express gene defects, whereas patients with focal $\mathrm{CHI}(\mathrm{CHI}-\mathrm{F})$ only express defects in a localised region of pancreas due to loss of a maternally-imprinted locus. Islet cell nucleomegaly - enlargement of the nucleus, has been described in association with $\mathrm{CHI}-\mathrm{D}$, but not $\mathrm{CHI}-\mathrm{F}$ nor a novel form of the disease - atypical $\mathrm{CHI}(\mathrm{CHI}-\mathrm{A})$. Our objectives were (1) to quantify islet cell nucleomegaly, (2) assess the incidence of nucleomegaly in control and $\mathrm{CHI}$ tissues, and (3) examine the association of nucleomegaly with proliferation.

\section{Methods}

Tissue was obtained following surgery from patients with $\mathrm{CHI}-\mathrm{D}(\mathrm{n}=9$ patients with $A B C C 8 / K C N J 11$ gene defects), $\mathrm{CHI}-\mathrm{F}$ ( $\mathrm{n}=5$ patients with $A B C C 8$ gene defects), $\mathrm{CHI}-\mathrm{A}$ ( $\mathrm{n}=3$ patients with unknown genetic causes of disease) and age-matched controls ( $n=8,2$-months to 36-months of age). High-content analysis of histological sections $(5 \mu \mathrm{m})$ and serial block face-scanning electron microscopy were used to quantify nuclear enlargement and determined the extent of nucleomegaly in islets and islet cells.

\section{Results 1 - The Magnitude of Islet Cell Nucleomegaly}
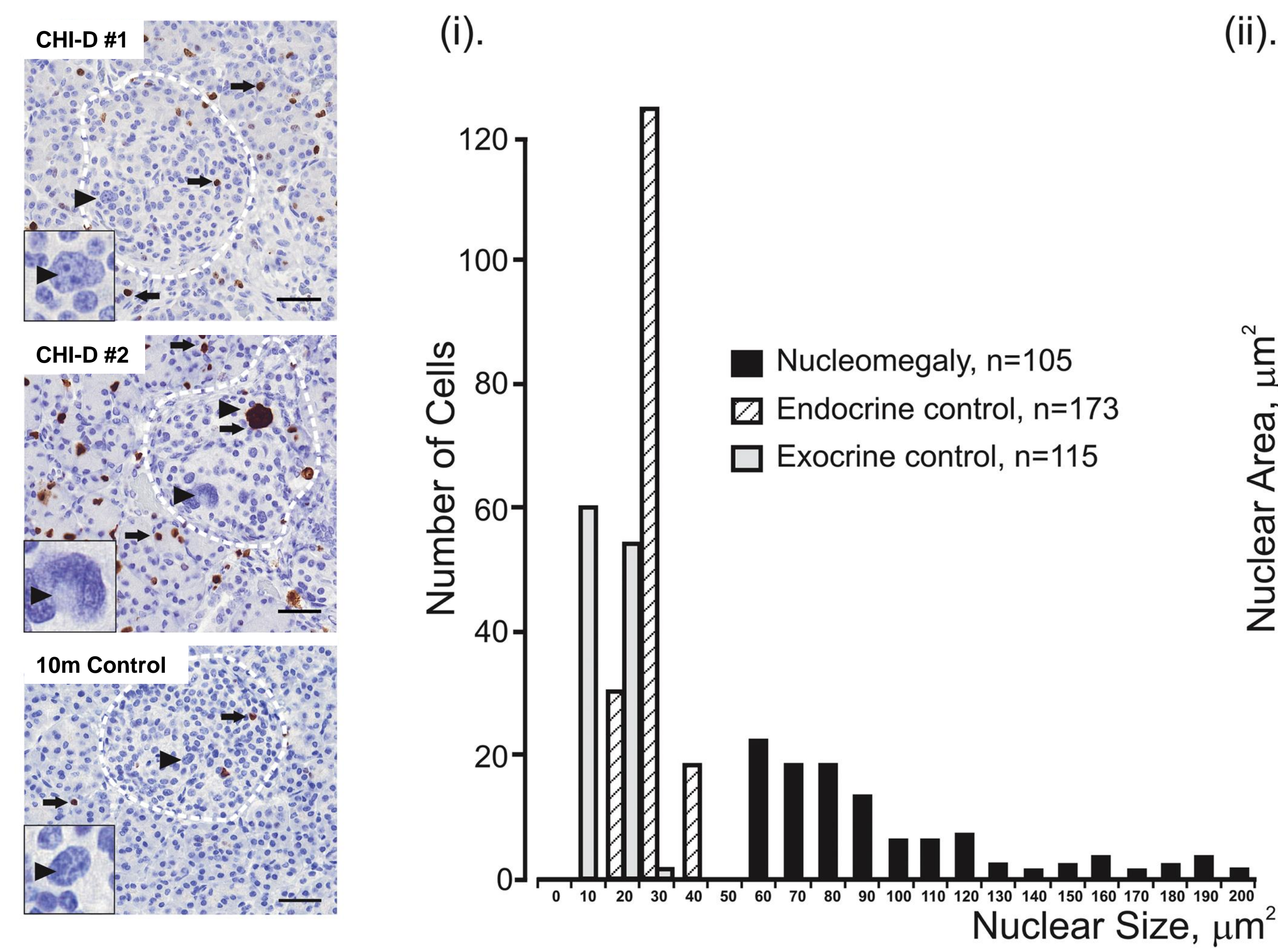

(ii).

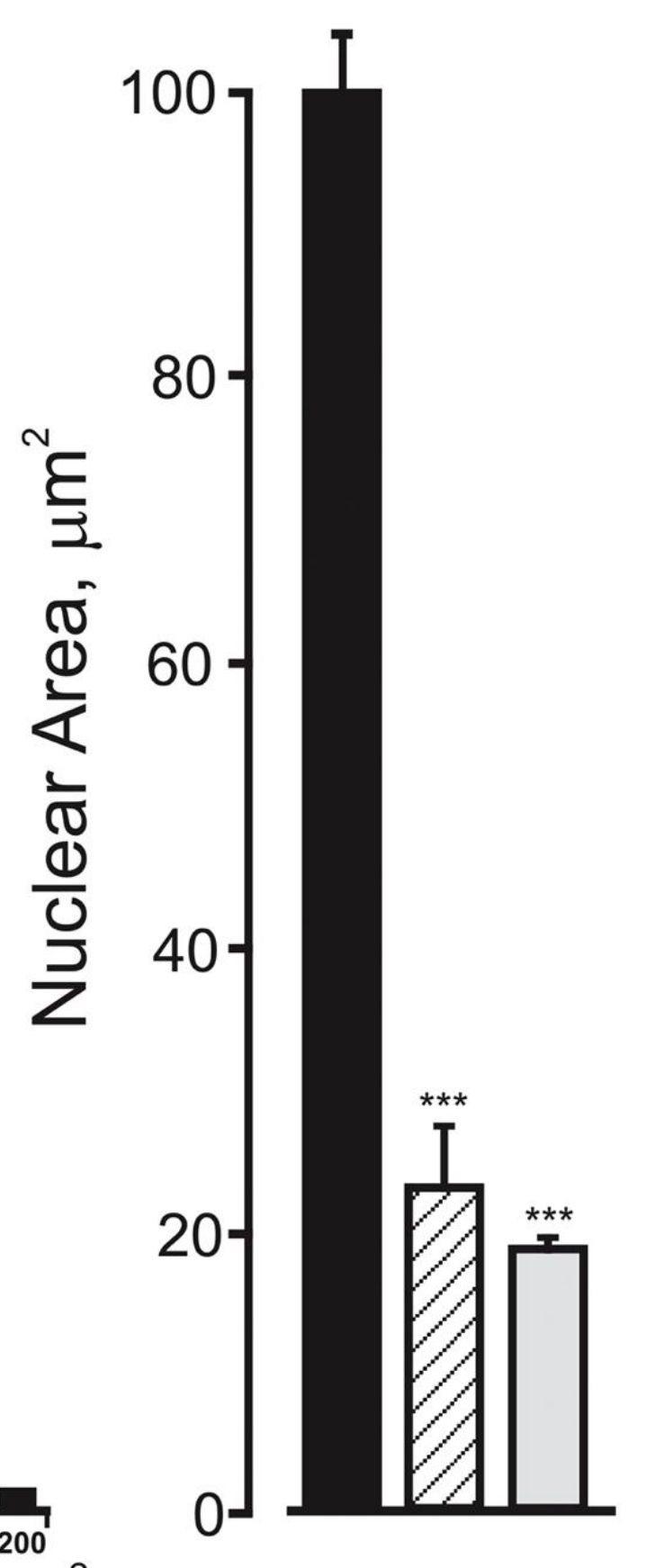

Typical images of nucleomegaly (arrowheads) in islets (dotted lines). Tissue sections were stained using the proliferation marker, Ki67 (filled arrows). Scale bar $=40 \mu \mathrm{m}$. The histograms provide a summary of nuclei surface area in $\mathrm{CHI}$ and control cells. (i) Distribution ranges of nuclear areas for endocrine control, exocrine control and nucleomegaly cells. (ii) Summary of the average areas of enlarged nuclei in islet cells with nuclei in both endocrine and exocrine cells. ${ }^{* * *} \mathrm{p}<0.001$
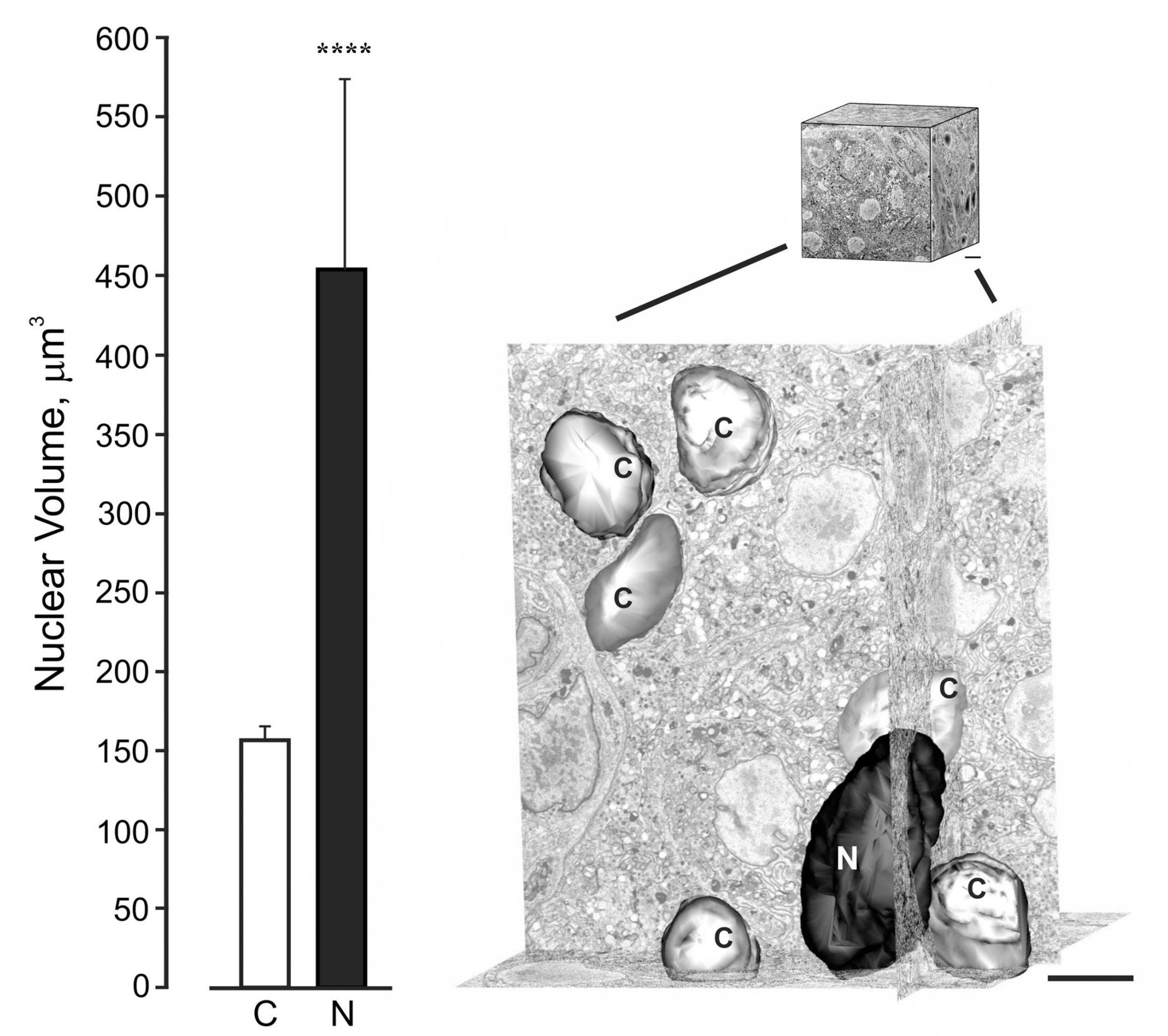

Nuclear volume estimates in $\mathrm{CHI}$ islet cells. (i) Average volume estimates of control nuclei $(n=30)$ and nucleomegaly $(n=4)$ in $\mathrm{CHI}$ islet cells. (ii) Serial block-face scanning electron microscopy data and digital reconstruction of control nuclei (C) and nucleomegaly $(\mathrm{N})$ in $\mathrm{CHI}$ islet cells. Note the marked increase in size of the enlarged nucleus. Scale bar $=2 \mu \mathrm{m} .^{* * * *}$ $\mathrm{P}<0.0001$.

\section{Acknowledgements}

We are grateful to Jacques Rahier and Christine Sempoux for help with the histopathology of the focal and atypical $\mathrm{CHI}$ cases in our studies.

\section{Results 2 - Nucleomegaly is Found in Endocrine Cells}

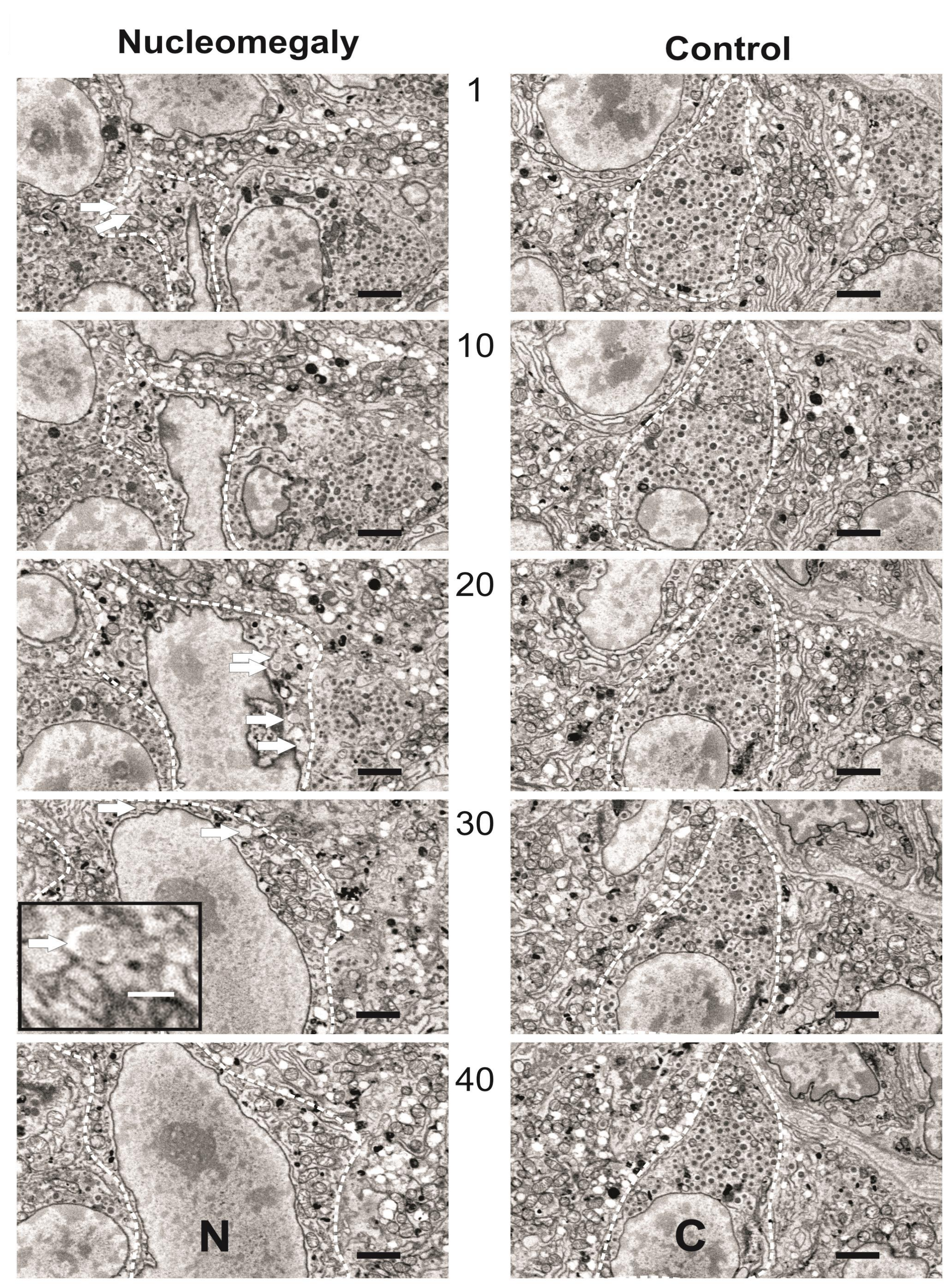

Image series from serial block face-scanning electron microscopy through adjacent parts of the same tissue. Note the limited number of secretory granules which were found in the cell with nucleomegaly (N). Typical secretory granules are indicated by the arrows and shown in more detail in the expanded image in section 30 . Note how extensive secretory granules are in the surrounding cells and in the control cell illustrated in the righthand montage $(\mathrm{C})$. For this dataset each image is separated by $1 \mu \mathrm{m}$. Scale bar $=2 \mu \mathrm{m}$; expanded image $=500 \mathrm{~nm}$.

\section{Results 3 - Nucleomegaly and the Diversity of CHI}

A.

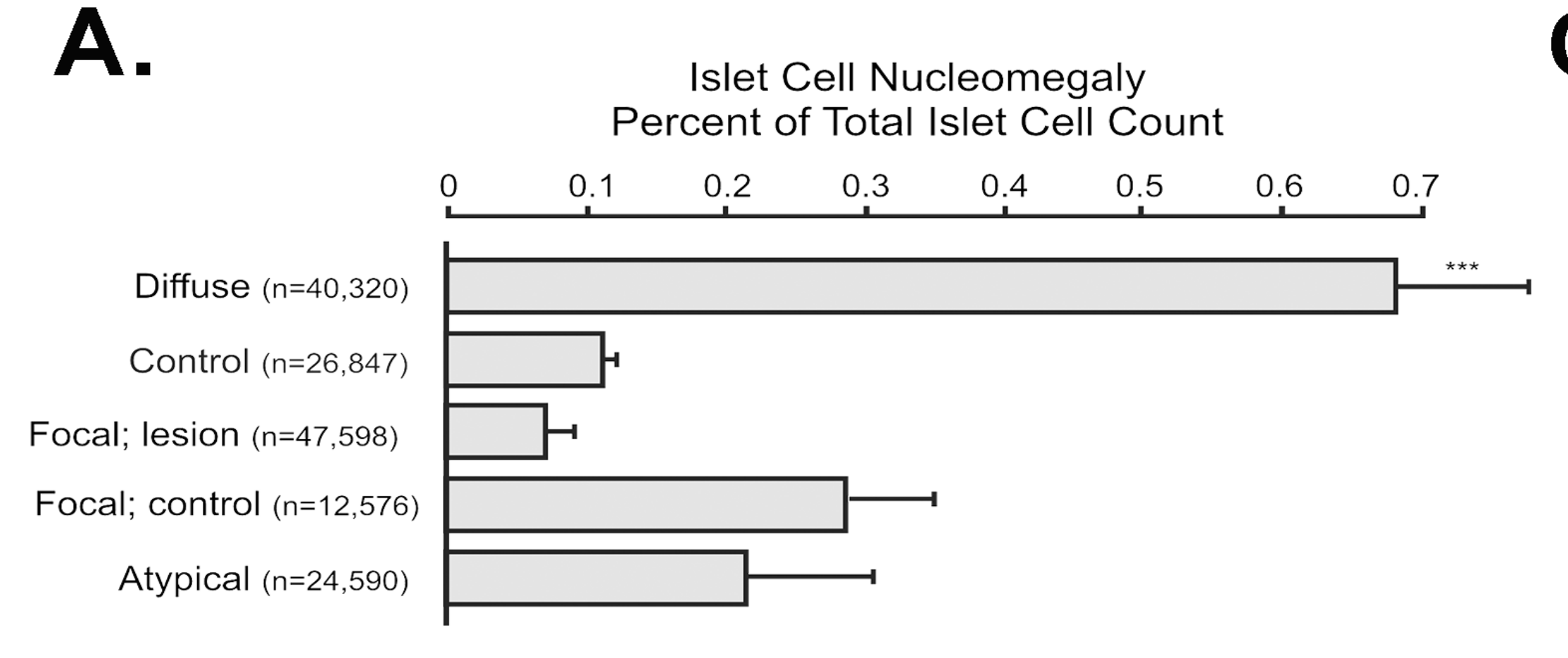

B.

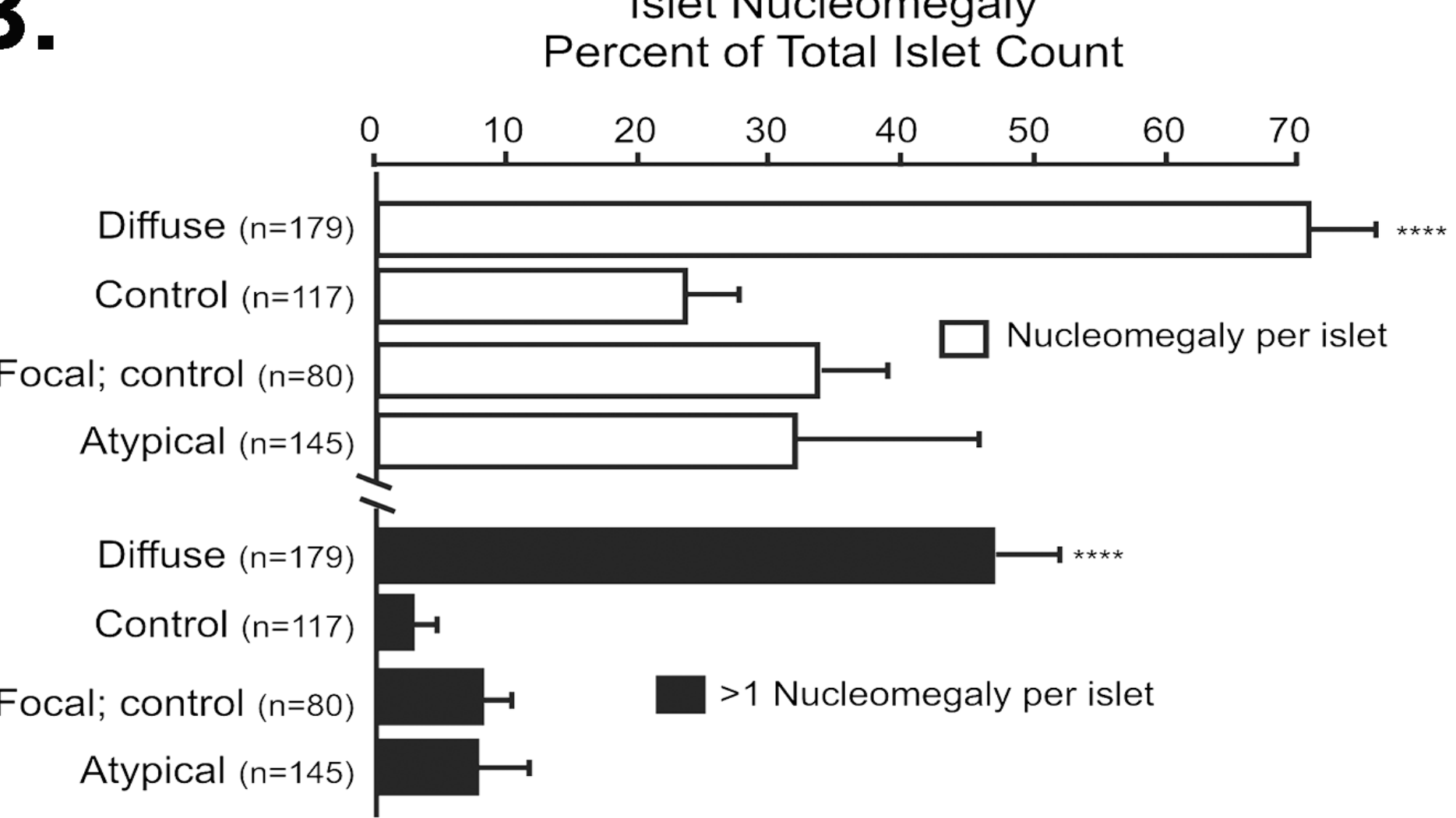

C.<smiles></smiles>

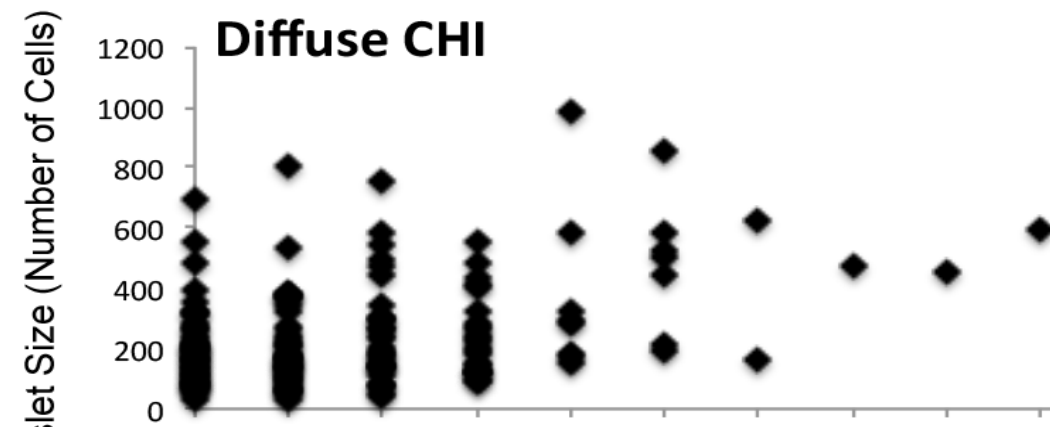

The incidence of islet cell nucleomegaly. (A) Incidence of nucleomegaly cells in the population of islet cells from $\mathrm{CHI}$ and age-matched control. ${ }^{* *}{ }^{*}<<0.001$. (B) Incidence of nucleomegaly-positive cells in islets. ${ }^{* *} p<0.001 ;{ }^{* * *} p<0.0001$. (C) The range of enlarged nuclei observed in islets for each cohort and the age-matched control group.

\section{Results 4 - Nucleomegaly and Cell Proliferation}

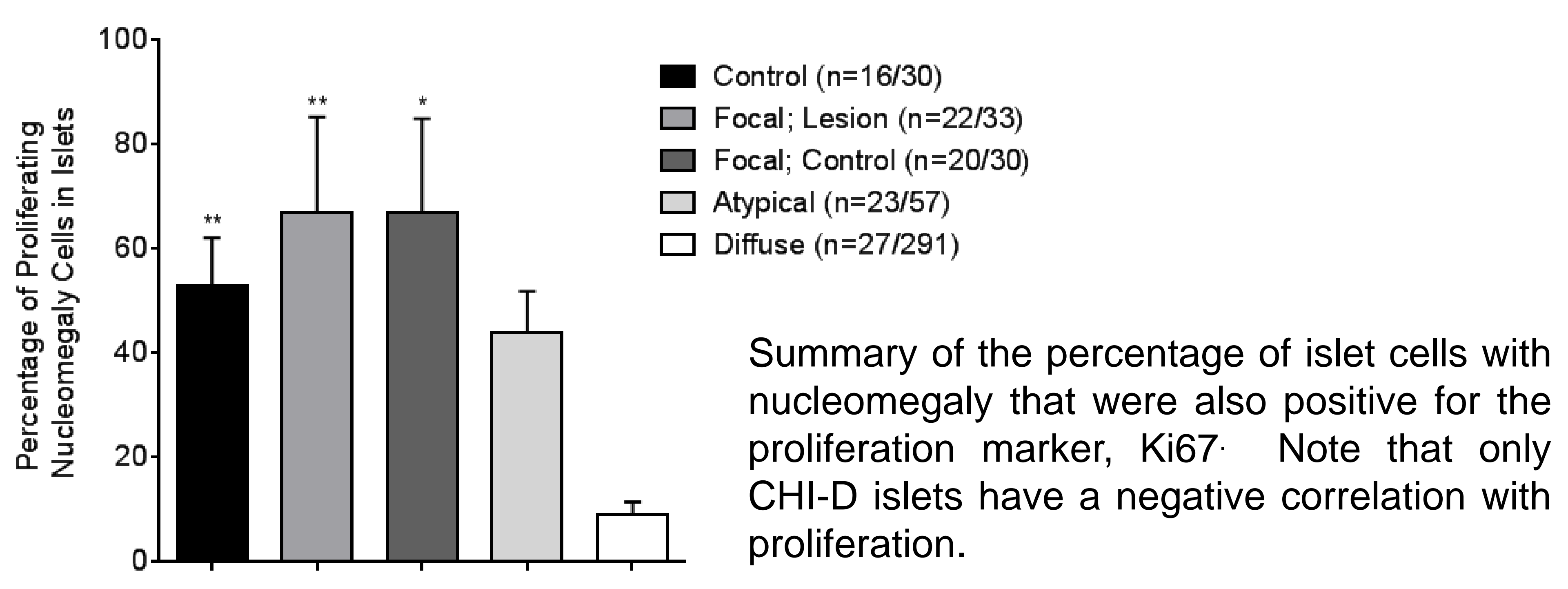

\section{Conclusions}

Islet cell nucleomegaly is a normal feature of the post-natal pancreas. Whilst cells with enlarged nuclei are pathognomonic for CHI-D and not other forms of disease, these cells are negatively associated with proliferation in diffuse disease suggesting a novel role in the pathobiology of this condition. 